\title{
The effectiveness evaluation of labor safety activities using driver's workplace as an example
}

\author{
A.V. Bogdanov ${ }^{1,2}$ and S.Yu. Popova ${ }^{1,2, *}$ \\ ${ }^{1}$ South Ural State Agrarian University, 454080, Chelyabinsk, Russia \\ ${ }^{2}$ South Ural University of Technology, 454000, Chelyabinsk, Russia
}

\begin{abstract}
There are many methods to determine the economic efficiency of implementing the labor safety activities. But in most cases, they cannot completely take into account the aggregate change in the effects of harmful and dangerous occupational factors on the human body before and after the implementation of relevant measures, and therefore they cannot give a fairly objective economic evaluation. This primarily relates to non-stationary workplaces, where production-related factors can be changed to a large extent during one shift. Therefore, it is expedient to evaluate economic efficiency for such jobs on the basis of the analysis of workers disease rate, which depends on the impact of all production-related factors on the human body. It is possible to distinguish production-related workers disease from the entire morbidity of employees including occupational injuries using the method of integrated assessment of working conditions through the losses of working time from morbidity with temporary incapacity for work (integrated assessment methodology). This technique can be used to calculate the economic efficiency when implementing labor safety activities at non-stationary workplaces (e.g. driver's workplace).
\end{abstract}

\section{Relevance}

All measures for improving the working conditions are developed to completely or partially eliminate the adverse effects of harmful and dangerous occupational factors on workers' health. A sufficient number of techniques are available to determine the economic efficiency of these measures. But in most cases, they do not take into account the aggregate change in the effects of harmful and dangerous occupational factors on the human body before and after the implementation of appropriate measures, and therefore cannot give a fairly objective economic evaluation. This primarily relates to non-stationary workplaces, where productionrelated factors can be changed to a large extent during one shift. But even in stationary workplaces, many production-related factors do not have constant values during one work shift: temperature and humidity, natural and artificial lighting, noise, vibration, labor related factors, etc. Therefore, it is expedient to evaluate the economic efficiency for stationary and especially for non-stationary workplaces using the analysis of workers morbidity, which depends on the combined effect of all production-related factors on the human body.

\footnotetext{
*Corresponding author: vetochka.79@mail.ru
} 


\section{Theoretical justification}

Currently, there are a number of methods for calculating the economic efficiency when implementing some labor safety activities. Economic analysis is considered in detail in the works of Shkrabak V.S. [1]. When applying some methods [2-5], which are the most suitable for both stationary and mobile workplaces (e.g. workplaces of truck drivers), the annual economic efficiency is determined as follows

$$
E=A \cdot\left(D_{1}-D_{2}\right),
$$

where $A$ is the average amount of damage, rubles/day; $D_{1}$ and $D_{2}$ are the losses of days due to employees' incapacity for work before and after the implementation of labor safety measures, days/year.

In order to carry out the calculations according to the expression (1), it is necessary to know the number of days of disability before and after the implementation of labor safety measures. This information is available in sick leave of employees in any company. But the disadvantage of the expression (1) is that the data from sick leave gives the information about all the workers' morbidity including those that is not related to the production process. It should be noted that workers' morbidity is conditionally divided into production-related and not related to the production process [6]. Therefore, when using the information from sick leave only, the morbidity that is not related to the production process can cause a significant error in calculating the economic efficiency.

\section{Research results}

It is possible to distinguish a production-related workers disease from the entire morbidity of employees including occupational injuries using the method of integrated assessment of working conditions on the basis of the standard for the losses of working time from morbidity with temporary incapacity for work (integrated assessment methodology) [6-8]. Productionrelated morbidity serves as a "measure" of conditions and labor safety, since their deterioration leads to an increase in production-related morbidity of workers, and vice versa. Production-related (limit-exceeding) incapacity for work (morbidity) of workers in general case is determined by the expression (2) [9]

$$
T I W_{L E}=T I W_{a}-T I W_{r},
$$

where $T I W_{a}$ is the average actual incapacity for work of employees in a structural unit (workplace, etc.), days/year; $T I W_{r}$ is the average regulatory (not related to the production process) incapacity for work in a structural unit (workplace, etc.), days/year.

It should be noted that the actual incapacity for work includes the morbidity caused by production-related and not related to the production process and is determined from the sheets (sick leave) of employees about their incapacity for work. Regulatory incapacity for work is not related to the production process (domestic) incapacity for work. It is determined from the directory of regulatory incapacity for work for each employee according to his/her sociodemographic indicators using a specially developed program [9, 10].

Before creating safer working conditions, the regulatory and actual temporary incapacity for work of employees are found as follows [11]

$$
\begin{aligned}
& T I W_{r}^{d}=\sum_{i=1}^{n} T I W_{r i}^{d} \\
& T I W_{a}^{d}=\sum_{i=1}^{n} T I W_{a i}^{d}
\end{aligned}
$$

where $T I W_{r}^{d}$ is the total regulatory temporary incapacity for work of employees until safer working conditions are created, people/days/year; $T I W_{a}^{d}$ is the total actual temporary 
employees incapacity for work until safer working conditions are created, people/days/year; $T I W_{r i}^{d}$ is the regulatory temporary incapacity for work of the $i$-th employee until safer working conditions are created, people/days/year; $T I W_{a i}^{d}$ is the actual temporary incapacity for work of the $i$-th employee until safer working conditions are created, people/days/year; $n$ is the number of people in the workplace (in a structural unit) until safer working conditions are created, people.

By analogy, it is possible to determine the regulatory and actual temporary employees' incapacity for work after creating safer working conditions [11]

$$
\begin{aligned}
& \operatorname{TIW}_{r}^{p}=\sum_{i=1}^{n} \operatorname{TI}_{r i}^{p} \\
& T I W_{a}^{p}=\sum_{i=1}^{n} T I W_{a i}^{p}
\end{aligned}
$$

where $T I W_{r}^{p}$ is the total regulatory temporary employees incapacity for work after (post) creating safer working conditions, people-days/year; $\operatorname{TIW}_{a}^{p}$ is the total actual temporary employees incapacity for work after creating safer working conditions, people-days/year; $T I W_{r i}^{p}$ is the regulatory temporary incapacity for work of the $i$-th employee after creating safer working conditions, people-days/year; $T I W_{a i}^{p}$ is the actual temporary incapacity for work of the $i$-th employee after creating safer working conditions, people-days/year; $m$ is the number of people at the workplace (in a structural unit) after creating safer working conditions, people.

Taking into account the expressions (2-6), a decrease in the average excess morbidity after creating safer working conditions $T I W_{a v}$ is determined as [12]

$$
T I W_{a v}=\frac{\sum_{i=1}^{n} T I W_{a i}^{d}-\sum_{i=1}^{n} T I W_{r i}^{d}}{n}-\frac{\sum_{i=1}^{m} T I W_{a i}^{p}-\sum_{i=1}^{m} T I W_{r i}^{p}}{m} .
$$

If the average cost of one man-day is known, then you can find the additional annual savings $E_{a d}$, which is observed after the creation of safer working conditions [12]

$$
E_{\mathrm{ad}}=T I W_{a v} \cdot C_{p . d .} \cdot m,
$$

where $C_{p . d .}=G_{\mathrm{c}} / \mathrm{T}$ is the average cost of one person-day, rubles/person-day; $G_{c}$ is the cost of gross output (work, services) for the year, rubles/year; $T$ is the number of man-days worked per year, people-days/year.

Then the annual economic effect $E_{\text {saf }}^{y}$ due to the creation of safer working conditions through the implementation of labor safety measures can be found from the expression [12]

$$
E_{\text {saf }}^{y}=E_{a d}-\frac{1}{P} \cdot C I_{\text {saf }} \cdot V_{\text {saf }},
$$

where $P$ is the payback period of capital investments in labor safety measures, years; $C I_{s a f}$ is capital investments in labor safety measures assigned to the unit of working time, rubles/unit of working time; $V_{\text {saf }}$ is the working time of a new variant during the payback period (after the implementation of labor safety measures), unit of working time.

Taking into account the formulas (7-9), the annual economic effect $E_{\text {saf }}^{y}$ will be determined from the expression [12]

$$
E_{s a f}^{y}=\left(\frac{\sum_{i=1}^{n} T I W_{a i}^{d}-\sum_{i=1}^{n} T I W_{r i}^{d}}{n}-\frac{\sum_{i=1}^{m} T I W_{a i}^{p}-\sum_{i=1}^{m} T I W_{r i}^{p}}{m}\right) \cdot C_{p . d .} \cdot m-\frac{1}{P} \cdot C I_{s a f} \cdot V_{s a f} .
$$

If one person works at his workplace (e.g. a truck driver), then the values of $n$ and $m$ in expression (10) will be equal $(\mathrm{n}=\mathrm{m}=1)$. Then expression (10) takes the following form

$$
E_{s a f}^{y 1}=\left(\left(T I W_{a 1}^{d}-T I W_{r 1}^{d}\right)-\left(T I W_{a 1}^{p}-T I W_{r 1}^{p}\right)\right) \cdot C_{p . d .} \cdot-\frac{1}{P} \cdot C I_{s a f} \cdot V_{s a f} .
$$




\section{Conclusion}

Using the obtained formula (11), it is possible to determine the annual economic effect for jobs where one person works. As an example, we make a calculation related to the improvement of the microclimate in the workplace when an electric heating device is mounted on the truck driver's seat. For calculation, we take $C_{p . d}=3000$ rubles/person-day and $P=5$ years. It should be noted that the values $T I W_{a 1}^{d}$ and $T I W_{r 1}^{d}$ for one person should be determined before the improvement of working conditions, and the values $T I W_{a 1}^{p}$ and $T I W_{r 1}^{p}$ should be defined one year after this upgrading. The calculation results are shown in table 1 .

Table 1. Initial data and the annual economic effect $E_{\text {saf }}^{y 1}$ obtained from implementing the measures when mounting an electric heating device on a seat in a vehicle

\begin{tabular}{|c|c|c|c|c|c|}
\hline $\begin{array}{c}T I W_{a 1}^{d}, \\
\text { people·days/ } \\
\text { year }\end{array}$ & $\begin{array}{c}\text { TIW } W_{r 1}^{d}, \\
\text { people·days/ } \\
\text { year }\end{array}$ & $\begin{array}{c}\text { TIW } W_{a 1}^{p}, \\
\text { people·days/ } \\
\text { year }\end{array}$ & $\begin{array}{c}T I W_{r 1}^{p}, \\
\text { people·days/ } \\
\text { year }\end{array}$ & $\begin{array}{c}C I_{\text {saf }} \cdot V_{\text {saf }}, \\
\text { rub. }\end{array}$ & $\begin{array}{c}E_{\text {saf }}^{y 1}, \\
\text { rub/year }\end{array}$ \\
\hline 17 & 3.9 & 9 & 4.4 & 4200 & 24660 \\
\hline
\end{tabular}

Thus, the calculation of the economic effect when using the method of integrated assessment of working conditions is applicable for any activities to improve labor safety and working places including the operators of motor cars (drivers of vehicles).

\section{References}

1. Shkrabak V.S. Labor safety. L.: Agropromizdat, 247 p., 1990.

2. Shkrabak V.S., Lukovnikov A.V., Turgiev A. K. Life safety in agricultural production. M.: KolosS, 512 p., 2004.

3. Mitrofanov P.G., Mitrofanov S.P. Ergonomic principles of labor safety in the agroindustrial complex: monograph. Kurgan, 420 p., 2006.

4. Galyanov I.V., Shkrabak V.S., Lapin A.P. On the issue of economic efficiency of machines taking into account the cost of safety. PP. 164-169, 1999.

5. Guidelines for determining the socio-economic efficiency of improving the conditions and labor safety in agriculture. Orel: VNIIOTX, 32 p., 1985.

6. Bogdanov A.V., Gorshkov Yu. G., Gankova O.A. Jobs certification using the method of integrated assessment. Labor safety and social insurance. No. 2. PP. 33-36, 2001.

7. Bogdanov A.V., Utkina S.V. Integrated assessment of working conditions. Improving labor conditions and safety in agriculture: ChSAU. PP. 25-33, 1990.

8. Gorshkov Yu.G., Bogdanov A.V., Gankova O.A. Jobs certification according to working conditions using the method of integrated assessment of working conditions based on the norm of working time losses from morbidity with temporary disability. M., PP. 120-125, 1999.

9. Bogdanov A.V. Safety improving and assessment enhancement of working conditions of mobile wheeled machine operators in agricultural production: dis. ... doctor of tech. sciences. St. Petersburg, 335 p., 2010.

10. Bogdanov A.V. Workplace certification according to working conditions using the method of integral assessment of working conditions based on the norms related to the working time losses from morbidity with temporary disability: Rospatent Certificate on the official registration of a computer program 2000611049 the Russian Federation. No. 2000610766; declared 07/17/00; publ. 10.10.00.

11. Bogdanov A.V. Economic efficiency evaluation of labor safety measures. Labor protection and safety equipment in agriculture. No. 11. PP. 56-57, 2005. 
12. Startsev A.V., Bogdanov A.V., Popova S.Yu. Evaluation of economic efficiency from introducing new equipment taking into account the changes in working conditions. Life safety. No. 8. PP. 42-44, 2006. 